\title{
Arthritis as the main or only symptom of hepatitis B infection
}

\author{
C. Pease and A. Keat \\ Department of Rheumatology, St Stephen's Hospital, Fulham Road, Chelsea, London SW10 9TH, UK.
}

\begin{abstract}
Summary: The clinical features of three patients who presented in different ways with inflammatory polyarthritis secondary to acute hepatitis B virus infection are discussed. The importance of early recognition of this condition is stressed.
\end{abstract}

\section{Introduction}

The occurrence of joint pain in the prodrome of viral infection is well documented. Up to a third of patients developing clinically apparent hepatitis B note significant rheumatic symptoms before jaundice appears (Steere \& Malawista, 1979). In spite of this, hepatitis B infection is seldom considered in the differential diagnosis of acute polyarthritis. Hepatitis Bassociated arthritis always precedes the onset of jaundice, sometimes by several weeks, and may be the only manifestation of infection. We present three patients who presented with severe joint pain and were found to have hepatitis $B$ infection. These cases illustrate the characteristic clinical features of this important and often missed diagnosis.

\section{Case reports}

\section{Case 1}

A 28 year old woman presented to the Casualty department with crippling joint pains. Four days earlier she had awoken with severe pain in both shoulder joints; subsequently the metacarpo-phalangeal (MCP) and proximal interphalangeal (PIP) joints, elbows, jaw, lumbar spine, hips and knees had also become painful. She felt generally unwell but had not recently travelled abroad nor been vaccinated; she denied drug abuse.

All joints were tender, with synovitis at the left knee and both wrists. She was tender in the right hypochondrium, but there was no hepatomegaly nor jaundice. Investigation revealed; serum aspartate transaminase (AST): 329 IU/1 (normal 5-40 IU/1), alkaline phosphatase: $51 \mathrm{IU} / 1$ (normal 20-100 IU/1), bilirubin: $9 \mathrm{mmol} / 1$ (normal $2-20 \mathrm{mmol} / 1$ ). The full blood

Correspondence: C.T. Pease, M.R.C.P.

Accepted: 20 September 1984 count (FBC), erythrocyte sedimentation rate (ESR) and prothrombin time were normal. Viral studies, however, revealed hepatitis B surface (HBs) antigenaemia. Figure la details her clinical and biochemical progress. In retrospect she admitted sexual contact 3 months earlier with a man who in the past had been a heroin addict and had recently had an episode of jaundice.

The joint symptoms were severe for about 2 weeks, being only partially relieved by anti-inflammatory drugs. However, after $15 \mathrm{~d}$, jaundice appeared and simultaneously joint symptoms resolved. Ten weeks after the onset of symptoms, HBsAg was no longer detectable in serum and she had developed antibodies to $\mathrm{HBc}$ antigen.

\section{Case 2}

A previously fit 35 year old man presented with a $14 \mathrm{~d}$ history of joint pains, beginning with a painful stiff neck and low back. During the next few days both wrists, elbows, shoulders, knees and all the MCP and PIP joints became painful. There was morning stiffness of $2 \mathrm{~h}$ duration but no fever nor rash. He felt unwell and was not able to work.

The PIP joints were swollen, but the others appeared normal. The liver was neither palpable nor tender, nor was he jaundiced. Serum AST was elevated but the bilirubin and alkaline phsophatase were normal; their subsequent course is shown in Figure 1b. $\mathrm{He}$ was found to have HBs antigenaemia. The FBC, ESR, latex test, autoantibody screen and prothrombin time were normal.

Subsequent questioning revealed no history of drug abuse, transfusions, travel abroad nor contact with people likely to have hepatitis. He never became clinically jaundiced. After 4 weeks his joint symptoms improved spontaneously. Four weeks later, antibody to $\mathrm{HBc}$ antigen was detected; $\mathrm{HBs}$ antigen was detectable for a further 3 weeks.

(C) The Fellowship of Postgraduate Medicine, 1985 

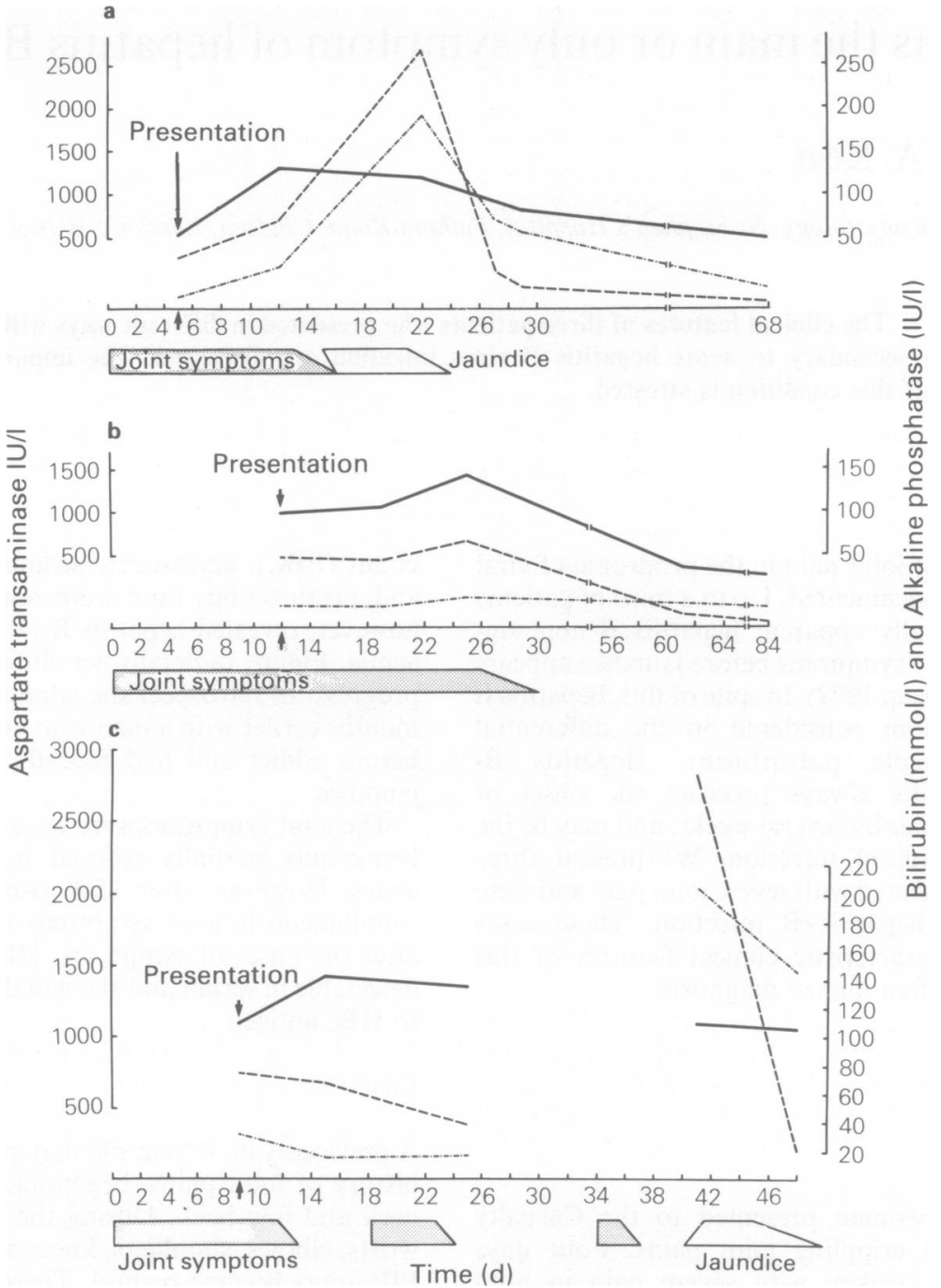

Figure 1 Duration of symptoms and their relationship to biochemical data in cases 1 (a); 2 (b); and 3 (c). Aspartate transaminase IU/l (----); bilirubin mmol/l (----); alkaline phosphatase IU/l (-).

\section{Case 3}

A 30 year old male heroin addict was admitted from the Casualty department chairbound, because of severe pain in all his joints, especially his back. Nine days earlier he had awoken with pain in his PIP and DIP joints of both hands; this was followed by arthralgia in the knees, neck and thoracic spine. He had been previously well, though $12 \mathrm{~d}$ earlier he had borrowed a needle from another heroin addict who, 4 weeks before, had experienced similar rheumatic sym- ptoms suggesting a short incubation period. However, earlier exposure to hepatitis B virus is possible.

On examination, he was afebrile, not jaundiced, but tender in the right hypochondrium. The only major joints free of pain were the wrist and temporo-mandibular joints. No synovitis was detectable. Initial investigations confirmed the presence of $\mathrm{HBsAg}$ in the serum, AST: $740 \mathrm{IU} / 1$, bilirubin: $33 \mathrm{mmol} / 1$, alkaline phosphatase: $115 \mathrm{IU} / 1$. After $6 \mathrm{~d}$ his pain subsided and he was discharged only to be re-admitted $3 \mathrm{~d}$ later with a recurrence of arthralgia and synovitis with effusion 
at the right knee. This episode subsided over $4 \mathrm{~d}$. His biochemistry was unchanged; serum complement levels were normal. Apart from one further brief episode of arthralgia he was well until the fortieth day from the onset when he became jaundiced, bilirubin: $205 \mathrm{mmol} / 1$, AST: $2820 \mathrm{IU} / 1$, alkaline phosphatase: $115 \mathrm{IU} / 1$. Figure $1 \mathrm{c}$ details his clinical and biochemical progress. He has since been lost to follow up.

\section{Discussion}

In each of these patients evidence of acute hepatitis B infection was demonstrated and other causes of their joint symptoms were, so far as possible, excluded. Hepatitis B arthritis is a recognisable clinical entity with some features which differ from other viral arthritides. The onset of joint pain is often dramatic, as in our patients, with several joints being involved at once in a symmetrical fashion. The PIP, knee, ankle and MCP joints are most frequently involved. Joint symptoms usually persist for no more than 2 weeks and in most cases the arthritis resolves with the onset of jaundice. In patients who remain anicteric, joint symptoms may be prolonged.

With the availability of highly sensitive tests, HB antigens are detectable in the serum within days of

\section{References}

ALPERT, E., ISSELBACHER, K.J. \& SCHUR, P.H. (1971). The pathogenesis of arthritis associated with viral hepatitis. New England Journal of Medicine, 285, 185.

INMAN, R.D. (1982). Rheumatic manifestations of hepatitis B virus infection. Seminars in Arthritis and Rheumatism, 11, 406.

KRUGMAN, S., OVERBY, C.R., MUSHAHWOR, I.K., LING, C., FROSNER, G.G. \& DEINHARDT, F. (1979). Viral hepatitis, type B: studies on natural history and prevention re- exposure and abnormal levels of liver enzymes in serum are detectable after about 8 weeks (range 6-11 weeks). Joint symptoms generally arise about 12 weeks (range 6-20 weeks) after exposure (Inman, 1982; Krugman et al., 1979).

Previous studies have found hypocomplementaemia and circulating immune complexes containing $\mathrm{HBsAg}$, complement, IgG, IgM and anti-HBsAg, suggesting that immune complex formation may be involved in the pathogenesis of the arthritis (Wands et al., 1975; Alpert et al., 1971).

The recognition of hepatitis $B$ as a cause of acute arthritis is important both for patient management and for the safety and protection of clinical and laboratory staff. There may be no history of contact with a likely hepatitis virus carrier. This condition may also represent a valuable clinical model of virus-induced arthritis in which research into pathogenetic mechanisms is facilitated by the presence of a known environmental agent.

\section{Acknowledgement}

We are grateful to Dr D. Barnardo, Queen Mary's Hospital, Roehampton and Dr R. Zeegan, St Stephen's Hospital, Chelsea for permission to report the case histories of the patients under their care.

examined. New England Journal of Medicine, 300, 101. STEERE, A. \& MALAWISTA, S.E. (1979). Viral arthritis. In Arthritis and Allied Conditions, 9th Edition, McCarty, D.J. (ed.), pp. 1391-1394. Lea and Febiger: Philadelphia.

WANDS, J.R., MANN, E., ALPERT, E. \& ISSELBACHER, K.J. (1975). Pathogenesis of arthritis associated with acute hepatitis B surface antigen positive hepatitis. Journal of Clinical Investigation, 55, 930. 